\title{
P-41 WERE GAS HYDRATES ASSOCIATED WITH MIOCENE-AGE COLD SEEPS OF THE APENNINES?
}

R. BARBIERI', P. AHARON' ${ }^{2}$, M. TAVIANI', F. RICCI-LUCCHI' and G.B. VAI'

'Bologna University, Dipartimento di Scienze della Terra e Geologico-Ambientali, Via Zamboni 67, 40126 Bologna, Italy ${ }^{2}$ Louisiana State University ${ }^{3} \mathrm{CNR}$

\begin{abstract}
Presently there is an emerging interest in ocean-based gas-hydrates (mixture of gas and water in ice form stable at high pressure and low temperature conditions) primarily related to concerns for global climate change and for future shortages in conventional fossil fuels (Kvenvolden, 1993). Athmospheric methane is radiatively active and as a greenhouse gas has a global warming potential 20 times greater than carbon dioxide. Because the amount of methane trapped in gas hydrates from ocean margins is about 3000 times the present amount in the atmosphere, even a fractional release of methane resulting from gas hydrate dissociation has the potential to significantly impact the radiative properties of the atmosphere and, consequently, alter the global climate. Massive sublimations of paleo-gas hydrates altering significantly the chemistry of the Earth atmosphere have recently been blamed for the unusual abrupt global warming at the end of the Paleocene and the warming spikes of the late Pleistocene unrelated to the Milankovitch astronomical forcing. The question of whether or not gas hydrates were associated with known occurrences of fossil hydrocarbon seeps has not yet been addressed. Here we evaluate the likelyhood of gas hydrates occurrence in the Marnoso-arenacea ocean basin and outline our study in progress aiming to develop criteria for recognition of paleo-gas hydrates in the Miocene-age Apenninic seeps.
\end{abstract}

Richly fossiliferous limestones, locally called "calcare a Lucina" (CAL), are common in the foredeep basins of the northern Apennines of Italy (Ricci-Lucchi and Vai, 1994; Conti and Fontana, 1999) (Fig. 1). The best outcrops of CAL (Figs. 2 and 3) were documented from the Marnoso-arenacea Formation were they occur at roughly regular stratigraphic intervals, from Langhian, through Serravallian and late Tortonian, to the early Messinian (Ricci-Lucchi and Vai, 1994). Evidence derived from field observations, petrology, fossil assemblages, and carbon isotopes indicate that $\mathrm{CAL}$ limestones represent fossil equivalents of extant hydrocarbon seeps (Taviani, 2000). The following arguments suggest that gas hydrates were likely to be present during CAL deposition.

(1) The turbidite infill of the foredeep basins were rich in organic material of terrestrial source and its maturation during rapid burial is typically prone to derivation of methane gas skipping the oil window (Mattavelli et al., 1983).

(2) Advection of methane-rich fluids through fault conduits on the seafloor is supported by (i) anomalous ${ }^{13} \mathrm{C}$-depleted values (up to $\partial^{13} \mathrm{C}=-58 \%$ PDB) in the aragonite splays (Fig. 4) and dolomicrites which preserve the imprints of hydrocarbon venting on the Miocene-age seafloor (Terzi et al., 1994), and ii) occurrence of fossil methanotrophic modiolid bivalves associated with CAL carbonate buildups (Taviani, 1994). 
(3) $\partial^{180}$, benthic foraminifera, and mollusk depth adaptations place the paleobathymetry of the CAL at upper to middle bathyal depths (200 to $800 \mathrm{~m})^{\prime}$ (Aharon and Sen Gupta, 1994; Taviani, 1994). These paleodepths correspond to bottom temperatures of 5 to $12^{\circ} \mathrm{C}$ and pressures of 20 to 80 atmospheres. Gas hydrates are the stable form at the lower temperature $\left(5-7^{\circ} \mathrm{C}\right)$ and higher pressure (50-70 atm) ranges.

We tentatively suggest that gas hydrates were likely to be associated with CAL deposition and were possibly an important source of methane to the Miocene atmosphere upon their sublimation. Our study in progress aims to develop rigorous criteria to identify the occurrence of paleo-gas hydrates on the basis of field observations, geochemistry and mineralogy, quantify the probable size of this methane source and its rate of release by sublimation into the atmosphere during the subsidence and thrusting associated with the Apennine orogeny.

\section{References}

Aharon, P. and Sen Gupta, B.K., 1994. Bathymetric reconstructions of the Miocene-age "Calcari a Lucina" (Northern Apennines, Italy) from oxygen isotopes and benthic foraminifera. GeoMarine Letters, 14: 219-230.

Conti, S. and Fontana, D., 1999. Miocene chemoherms of the Northern Apennines, Italy. Geology, 27: 927-930.

Kvenvolden, K.A., 1993. A primer on gas hydrates. In: Howell, D.G. (Ed.), The Future of Energy Gases. United States Geological Survey Professional Paper, 1570: 279-291.

Mattavelli, L., Ricchiuto, T., Grignani, D., and Schoell, M., 1983. Geochemistry and habitat of natural gases in Po Basin, northern Italy. American Association of Petroleum Geologists Bulletin, 67: 2239-2254.

Ricci-Lucchi, F. and Vai, G.B., 1994. A stratigraphic and tectonofacies framework of "Calcari a Lucina" in the Apennine Chain, Italy. Geo-Marine Letters, 14: 210-218.

Taviani, M., 1994. The "Calcari a Lucina" macrofauna reconsidered: deep-sea faunal oases from Miocene-age cold vents in the Romagna Apennines, Italy. Geo-Marine Letters, 14: 185-191.

Taviani, M.; 2000. Fluid venting and associated processes. In: Martini, P. and Vai, G.B. (Eds.), Anatomy of an Orogen: The Apennines and Adjacent Mediterranean Basins. Kluwer Academic Publishers (in press).

Terzi, C., Aharon, P., Ricci-Lucchi, F., and Vai, G.B, 1994. Petrography and stable isotope aspects of cold-vent activity imprinted in Miocene-age "Calcari a Lucina" from Tuscan and Romagna Apennines, Italy. Geo-Marine Letters, 14: 177-184. 


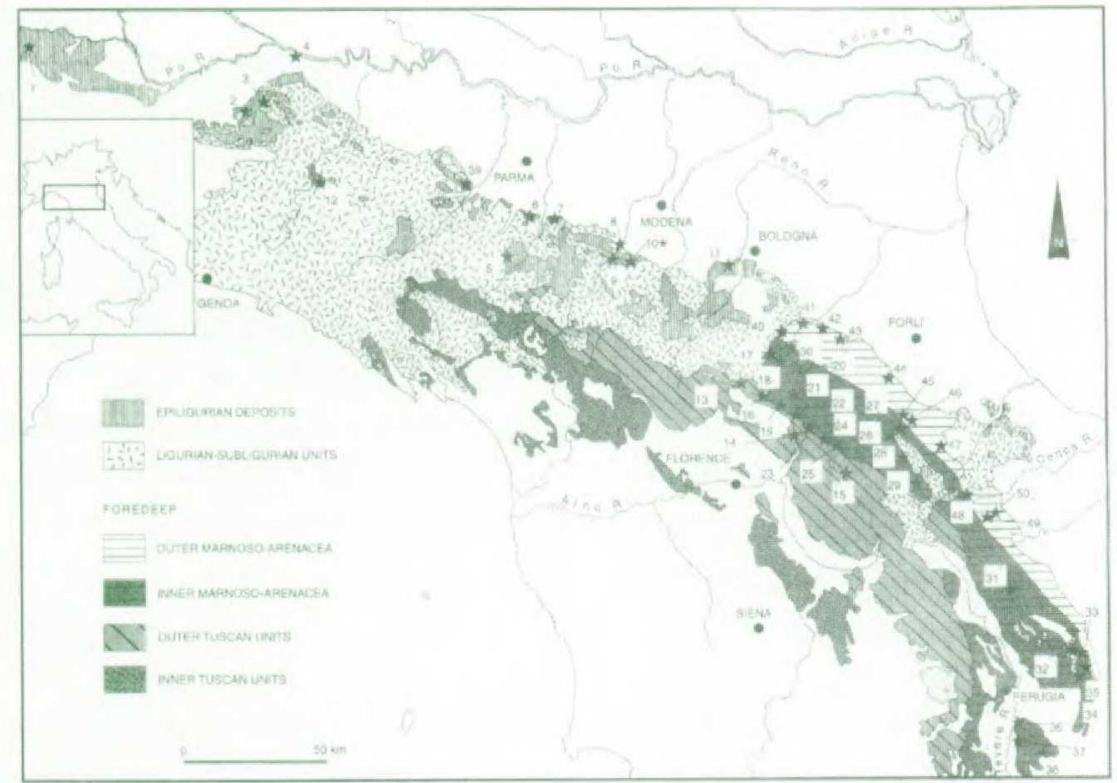

Fig. 1. Distribution of Miocene-age "calcari a Lucina" limestones in the turbidite-filled foredeep basins of the northern Apennines (after Conti and Fontana, 1999)

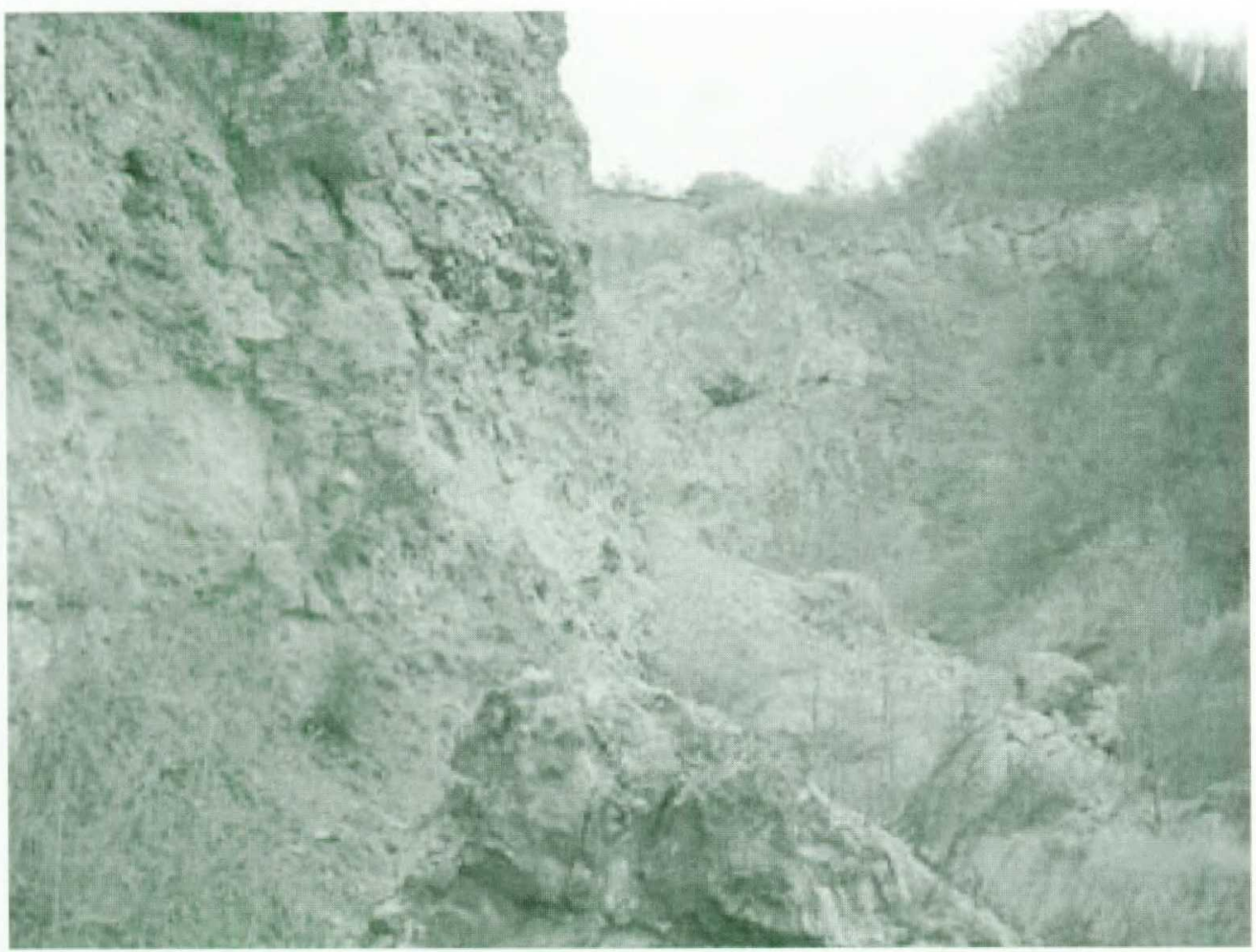

Fig. 2. Typical CAL limestone outcrop from northern Apennine 


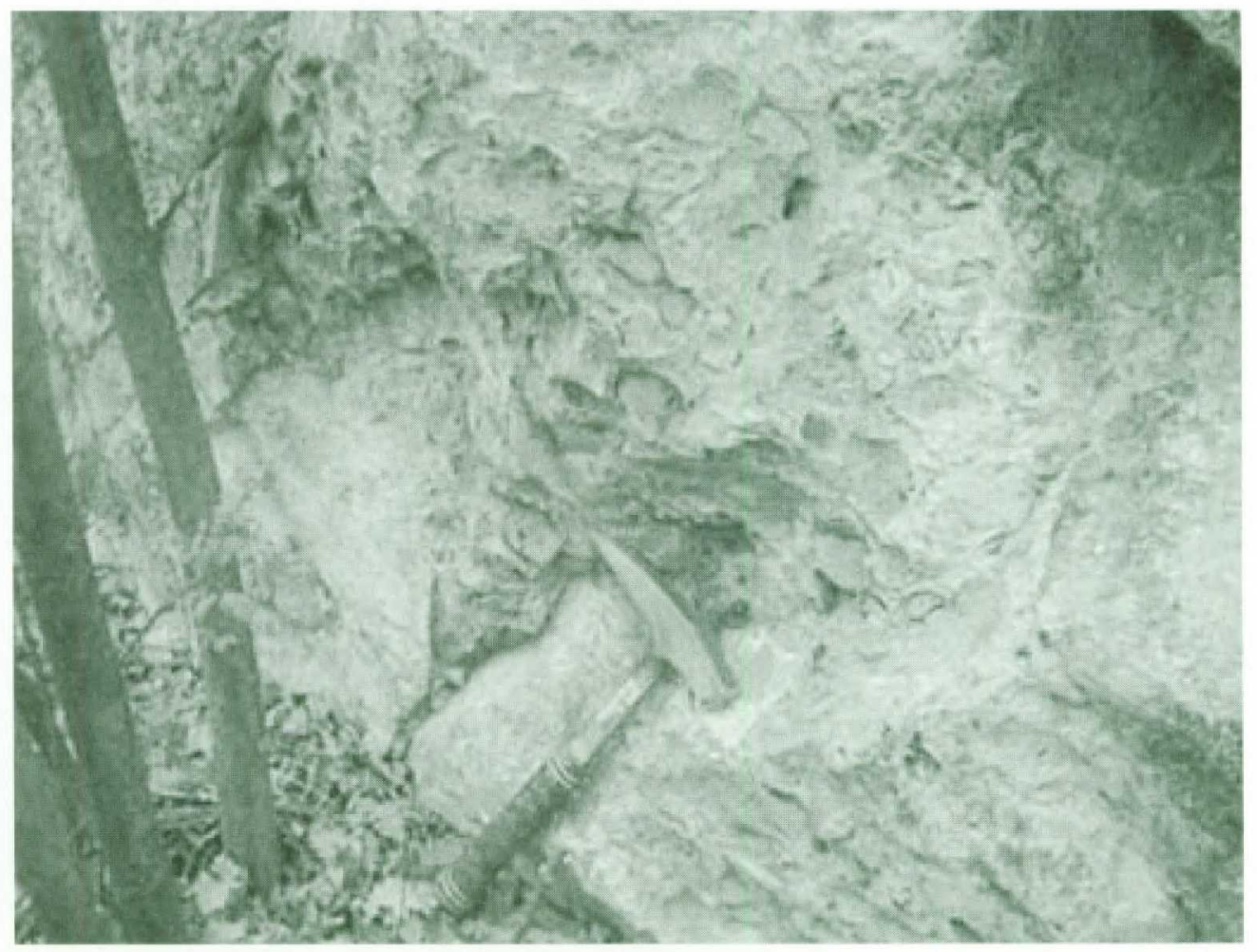

Fig. 3. Densely packed, lucinid bivalve shells from CAL limestone, northern Apennine

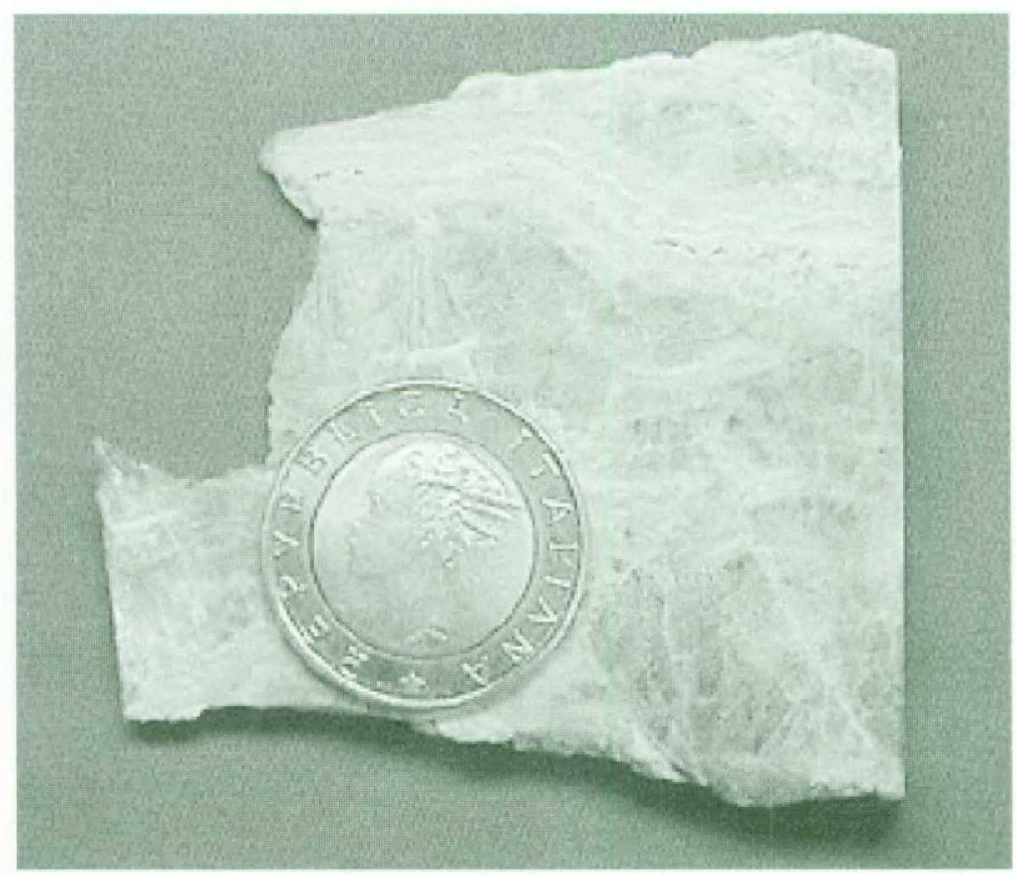

Fig. 4. Aragonite cement with strongly negative $\partial{ }^{13} \mathrm{C}$ composition (-50\% PDB) from CAL outcrop of the Romagna Apennine 